\title{
Constructing the Past: the Relevance of the Narrative Self in Modulating Episodic Memory
}

\author{
Roy Dings ${ }^{1}$ (D) $\cdot$ Albert Newen ${ }^{1}$ (D) \\ Accepted: 29 July 2021/Published online: 13 August 2021 \\ (C) The Author(s) 2021
}

\begin{abstract}
Episodic memories can no longer be seen as the re-activation of stored experiences but are the product of an intense construction process based on a memory trace. Episodic recall is a result of a process of scenario construction. If one accepts this generative framework of episodic memory, there is still a be big gap in understanding the role of the narrative self in shaping scenario construction. Some philosophers are in principle sceptic by claiming that a narrative self cannot be more than a causally inefficacious attributed entity anyway. Thus, we first characterize a narrative self in detail and second we clarify its influential causal role in shaping our episodic memories by influencing the process of scenario construction. This happens at three stages, namely at the level of the input, the output and the process of scenario construction.
\end{abstract}

Keywords Narrative self $\cdot$ Episodic memory $\cdot$ Scenario construction $\cdot$ Self-memory systems

\section{The Missing Link in the Debate on Memory and Narrative Selfhood}

It is commonly held that memory contributes to our sense of self, or that memory plays a constitutive role in our narrative selfhood. Such views are prevalent both in philosophy (cf. Macintyre 1981; Schechtman 2007; Hutto and McGivern 2016; McCarroll 2018) and psychology (cf. Conway, Singer and Tagini 2004; Conway 2005; Prebble, Addis and Tippett 2013). The current paper focuses on the reverse relation, which has received far less attention: How does the narrative self modulate our episodic memory?

Roy Dings

roy.dings@rub.de

Albert Newen

albert.newen@ rub.de

1 Institute of Philosophy II, Ruhr Universität Bochum, Universitätsstrasse 150, D-44801 Bochum, Germany 
For instance, do narratives we formulate about ourselves impact the encoding, storage, accessibility or retrieval of episodic memories? Can a narrative self change the core content of an episode that we remember? Could it be the case that whether or not an object serves as a cue for retrieval, depends on the narrative of that person? We aim to demonstrate and characterize the systematic influences of the narrative self on episodic memory.

In Section 2 we will argue that we need such a theory of influences of the narrative self on episodic memory: it will prove the relevance of the narrative self (in the philosophical debate) and change our view on mental time travel (in cognitive science). To set the stage for the discussion, we use Section 3 to demarcate our approach and to offer characterizations of the relevant aspects, i.e. selves, narratives, episodic memory and the individuation of events. In the key Section 4, we put forward a theoretical framework for self and memory which is able to accommodate recent empirical investigations into how narrative selves modulate memory. We presuppose a framework of constructive memory such that episodic memory includes a central process of scenario construction (Cheng, Werning and Suddendorf 2016). We discuss three routes of influence of the narrative self on episodic recall, namely modifying the output, the process and the input of scenario construction. The result is a self-memory system that does justice to the bidirectional interrelation of self and memory. In Section 5 we offer several empirical predictions that follow from our account. We end in Section 6 by summarizing the advantages of our account.

\section{The Relevance of Clarifying the Influence of Narrative Selves on Memory}

A detailed theory of the influence of the narrative self on episodic memory has at least the following important consequences: (i) we could rebut radical scepticism about any causal role of the narrative self, (ii) we could update or modify the account of future projections and of mental time travel in general and clarify the relation between episodic remembering and episodic future thinking, (iii) we would gain a factor that would allow us to elucidate systematic individual differences in episodic recall. Let us shortly elaborate on these motivations:

First, we need a theory of influences of the narrative self to overcome radical sceptics who question the relevance of narrative selves for theories on the self (e.g. Strawson 2004; Metzinger 2003). One example is Galen Strawson, who has written a series of papers and books arguing against what he calls the Psychological Narrativity Thesis (Strawson 2004, 2018, 2020). ${ }^{1}$ According to Strawson the self is not narrative but experienced in our short window of consciousness realized by working memory. We consider the main thrust of Strawson's (2020) sceptical view to be twofold. On the

\footnotetext{
1 This thesis entails, roughly, "that human beings typically see or live or experience their lives as a narrative or story of some sort, or at least a collection of stories" (Strawson 2004, p.428). We say 'roughly' because there are various flavours of narrativity (see e.g. Schechtman 2007 for a discussion) and hence PNT can be spelled out in various ways as well (as Strawson 2020 acknowledges). Moreover, we think that even if PNT is not valid for every person (as Strawson would presumably argue) it is still valid for the majority of people, which means that it is still important to show the relevance of the narrative self in standard episodic memory, i.e. to rebut any radical scepticism.
} 
one hand, Strawson holds that narrative does not 'permeate our experience' and that our lives are not lived narratively (pace e.g. Schechtman 2007). On the other hand, he questions whether narrativity does anything: on Strawson's view we can fully understand cognitive systems without invoking narrative selves. A central aim of our account is to rebut this challenge by clarifying how the narrative self modulates our memory in everyday cases. Moreover, our endeavour is able to deal with the sceptical line of reasoning, which highlights that key narrative theorists tend to postulate the influence of narrative self on memory, or implicitly assume it, but do not explicate it. It is only fair of Strawson to remain sceptical until there is a proper elaboration on how narratives about ourselves (i.e. self-narratives) purportedly influence our psychology. As we will show in Section 4, there actually is empirical evidence supporting such an influence, and we will put forward an integrative framework that will advance the philosophical debate by validating the influence and relevance of self-narratives.

Secondly, our integrative framework of influences of the narrative self forces us to update or modify the account of future projections and of mental time travel. Future projection and episodic memory are not independent cognitive abilities but seem to be closely connected via mental time travel (for a discussion see Michaelian 2016). Future projection is considered to have similar mechanisms as 'past-projection' (cf. Hassabis and Maguire 2007; Schacter and Addis 2007; Suddendorf and Corballis 2007). On this line of thinking, people have one capacity for mental time travel, and this one capacity enables us to project our selves into the past (re-experiencing an event) or into the future (pre-experiencing an event). If we can demonstrate a crucial role of the self in episodic memory, we should expect it in future projections as well. But so far, the role of the self in these acts remains to be properly investigated.

A first move was recently made by Martin Conway to update his influential theory on the Self-Memory System (SMS, cf. Conway \& Pleydell-Pearce 2000; Conway, Singer and Tagini 2004; Conway 2005) in order to accommodate such future selfprojections (cf. Conway, Justice and d'Argembeau 2019). In this revisited SMS, both core elements of the model (the conceptual self and the autobiographical knowledge base $^{2}$ ) contain past- as well as future-directed components: the conceptual self is updated to entail both past and future selves, and the autobiographical knowledge base, which previously included only past lifetime periods and past general events, now also includes anticipated lifetime periods and anticipated general events. The original SMS included narrative life stories (cf. Bluck \& Habermas 2000) which functioned as the 'highest' level of integration of information. In the revised SMS, there is still only one life-story schema including both, past- and future directed self-narratives. The suggested revision to the SMS puts pressure on clarifying the exact role of self-narratives in modulating memory, because that might have implications for their future-oriented counterparts (Hardt 2018; Hutto and McGivern 2016). These implications should be expected because research shows that both memory processes and self-related processes (including self-narratives) together shape how one anticipates future events, such as

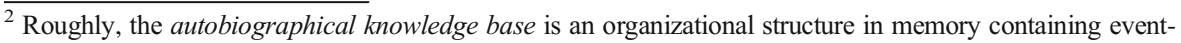
specific knowledge as well as more abstracted general events and even more generalized lifetime periods. The conceptual self consists of (semantic) knowledge of patterns of the self (e.g. behavior, traits). During retrieval, the conceptual self may guide a memory search by providing a schema which the information has to fit. During encoding, the working self (which may be seen as the online instantiation of the conceptual self) modulates the active goals and may thereby affect the processing of self-relevant information.
} 
the level of detail or valence associated with that future episode (cf. Grysman et al. 2013; Demblon and d'Argembeau 2017; Özbek et al., 2017; Ernst and Rathbone 2019).

Third, the influences of narrative selves on episodic memory may enable us to account for individual differences in findings about episodic recall. For instance, it has been shown that there are such individual differences in how self-defining memories and future projections are organized (cf. d'Argembeau, Lardi and Van der Linden 2012; Demblon and d'Argembeau 2017), suggesting that people might have a personal 'style' of organising self-defining events in both past and future. We want to argue that narrative selves offer a good candidate to make sense of those individual differences and personal styles of organisation. Indeed, self-narratives are excellent examples of how individuals differ in their meaning-making and ascribing relevance to different events depending on their diachronic concerns. This is in line with previous suggestions according to which self-narrativity allows us to get at individual cases (cf. Singer and Bluck 2001; Rubin et al. 2019). Indeed in the SMS framework investigating individual differences would entail looking at the individual's goals and self-concept, and it is the life-story that integrates these over time (Conway, Singer and Tagini 2004). Moreover, individual processing styles are closely related to the person's selfnarrative (Bouizegarene and Philippe 2016). Finally, Berntsen, Hoyle and Rubin's (2019) recent 'Autobiographical Recollection Test' puts a lot of emphasis on narrativity as a way of accounting for individual differences in autobiographical memory (see also Rubin et al. 2019).

Thus, we have at least three reasons to clarify the influence of the narrative self on episodic recall. To develop our account, we first introduce a clear account of the core concepts presupposed for the debate (Section 3) and then develop a theory of the main influences of the narrative self (Section 4).

\section{Demarcating Self, Narrative, Events and Memory}

To set the stage for our new proposal, we need an account of narrative selves which we develop in the context of the pattern theory of self (Section 3.1). Furthermore, we lay out a general understanding of constructive memory as scenario construction (Section 3.2) and use insight from action theory concerning the conceptualization of events (Section 3.3). Acknowledging the conceptualization of events is important for clarifying the influence of the narrative self on episodic recall in a way that bypasses Strawson's worries (Section 3.4).

\subsection{An Underlying Account of Self and Narrativity}

Is there a minimal consensus on theories of the self? If we leave aside theories which deny the existence of a self (arguments against such theories can be found in Newen 2018), then there still remains a large variety of theories of the self. Many famous theories focus on one aspect of the self, e.g. the narrative aspect (Dennett 1993) or the experiential aspect at the present time (Strawson 2018). This seems to be a shortcoming since as soon as theoreticians account for the ontogenetic development of self-understanding, the multiplicity of aspects which are constitutive of a self is obvious (Neisser 1988; Bermudez 2000; Newen 2018). Moreover, various memory researchers have 
similarly highlighted the shortcomings of focusing on one aspect of the self (Prebble, Addis and Tippett 2013; Libby and Eibach 2011; Ernst and Rathbone, 2019). What remains disputed is which aspects are relevant in line with ontogenetic evidence and how they are interconnected. A principle answer to this challenge is developed in the multifactorial pattern theory of the self which we think it therefore a plausible framework as a consistent and empirically anchored account of the self.

The pattern theory approach construes the self as multidimensional and integrative, with the narrative self as one of those dimensions (cf. Gallagher 2013; Newen 2018). On this approach, the self is best thought of as an integrated pattern of multiple characteristic self-aspects (e.g. affective, agentive, expressive, cognitive, narrative, etc.) that is dynamically modulated by the engagements of the embodied biological being with its social and physical environment. In other words, the self is a pattern of self-aspects realized in a body (as opposed to being something, an entity, that has these self-aspects, cf. Gallagher 2013), and any changes in the configuration of such a pattern constitutes a change in self. Thus, the pattern theory of self accepts a strongly variant and changing self which is anchored in the body and unified by integration processes to which memory is crucial (Newen 2018). Such changes in the self typically come about when the embodied agent interacts with its environment.

The role of narrative self-aspects within such a pattern theory approach pertains to integration over time (cf. Newen 2018; Gallagher and Daly 2018). Indeed any embodied human self with a normally developed memory is temporally extended: it has a certain past and (anticipated) future. It sets long-term goals and has to monitor and evaluate those diachronic concerns, and flexibly adapt when circumstances change. Moreover, it has to accomplish that in a meaningful and intelligible way, providing reasons (or confabulations) for why it acts the way it does. This is accomplished by the narrative self-aspects of the pattern (or, more colloquially put, 'the narrative self'). Thus, the narrative self is a part of the self-model that the embodied system (i.e. the biological being) relies on to organize information and to determine relevant courses of action. $^{3}$ Such a model consists of various more or less interwoven narratives about oneself in which past, present and future are integrated, based on the temporally extended concerns and the ever-changing circumstances. ${ }^{4}$ Importantly, the pattern

\footnotetext{
${ }^{3}$ Within philosophical research on narrativity, some have worried about the authorship problem which entails, roughly, the question of whether the narrative self is to be construed either in terms of the result of our narrative efforts (i.e. the narration) or in terms of the agent carrying out those efforts (i.e. the narrator) (for a discussion see Rau, 2016). We think this dilemma rests on a false assumption that we deny: from a diachronic perspective, disentangling the narrator from the narration is the wrong perspective. We suggest that the relation is a part-whole relation. The narrative self is part of the self-model which is an integrated pattern of characteristic features. This avoids the dilemma and we can account for the following observation: we narrate experiences that result in a particular self-narrative, but any subsequent narration is done from the perspective of that previously established self-narrative. Thus we side with an approach that seems more prevalent in psychology, where 'selves create stories which create selves' (Wilson \& Ross, 2003; McLean, Pasupathi \& Pals, 2007; Ernst \& Rathbone, 2019) and people can be at the same time the author of their self-narrative as well as the actor that realizes that self-narrative. This fits our emphasis on the embodied self as that which grounds a self-pattern, because it shows that the narrative self is not 'merely' an abstract self-narrative but is strongly intertwined with our bodily agency (Dings 2019).

${ }^{4}$ Importantly, the narrative self-model is flexible in the sense that it allows us to accommodate changes, but it is also rigid in that it is not modified after each act of narration. Not everything we say about ourselves immediately becomes a part of our self-narrative. Rather, information has to be integrated in the self-narrative, which may require time, repeated narrations and, sometimes, cognitive effort or external scaffolding.
} 
theory can not only account for this variance but enables us to describe slowly changing and fast changing dimension of the self: narrative selves anchored in long-term memory are part of our slowly changing self while the activation of these narrative selves in working memory is highly context-sensitive. We do not always activate all the contents of the narrative self but only the contextually relevant aspects of it. Those may then be modulated by situational experiences. Most importantly, the relevant unit to consider as influencing our episodic recall is the contextually relevant part of our self-narratives (Newen 2018).

In fulfilling the task of integration, the narrative self relies heavily on memory processes. And indeed the narrative self is typically used in memory research to account for integration (cf. Singer and Blagov 2004; Conway 2005; Libby and Eibach 2011). For instance, the narrative self might draw on past episodes to maintain a sense of selfcontinuity (Bluck 2003). How the narrative self is based on memory is a complex issue. The present paper is concerned with the reverse line of influence, i.e. how the narrative self modulates episodic recall.

\subsection{Demarcating Memory}

Empirical and theoretical research on memory has suggested a diverse set of taxonomies and distinctions to demarcate memory systems. An overall trend in the past few decades of memory research has been to emphasize the fact that episodic memory does not consist of simply reactivating a stored episode but rather that recalling an event involves constructive processes which may modify the original episode. In this respect, various memory frameworks have highlighted that episodic memory may be generative (Conway 2005), that we construct or reconstruct particular episodes (Schacter and Addis 2007) or that we engage in a sort of scene construction when remembering (Hassabis and Maguire 2007). Our proposal fits this trend of emphasizing the reconstructive nature of memory, yet our account of influences of the narrative self does not presuppose any particular constructive framework. Nevertheless, we have a preferred background theory, namely the framework of scenario construction (see e.g. Cheng, Werning and Suddendorf 2016; Cheng and Werning 2016). Roughly, this framework suggests that a process of scenario construction starts when a cue triggers retrieval, thereby activating, on the one hand, the episodic memory trace containing the gist of an episode, and on the other hand semantic information that is relevant to that retrieval cue and the activated gist (cf. Figure 1). Importantly, the episodic memory trace and the semantic information may interact to enrich the gist to a full scenario that is recalled. Importantly, the Scenario Construction framework is a model of diachronic memory processes, so any constructed scenario may feed into subsequent instances of scenario construction by affecting the gist or semantic information.

The Scenario Construction Framework provides an empirically grounded model which may serve as a starting point for developing our account. However, to clarify the influence of the narrative self on such scenario construction we revise this initial model in several respects. First, it is helpful to conceptually distinguish between the input, process and output of scenario construction. The input is the retrieval trigger; the process pertains to the activation of the gist and the enrichment of this gist via semantic information; the output consists of a constructed scenario. In Section 4 we will argue that the narrative self may influence the input, output and process of scenario construction. A second revision that we propose is to further specify the components of a 


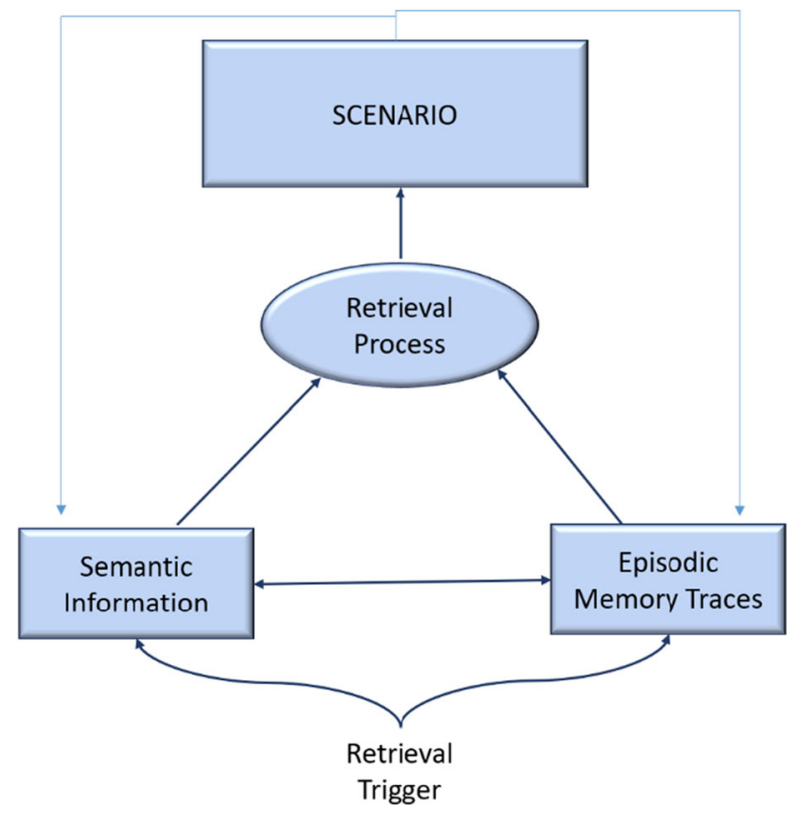

Fig. 1 The Scenario Construction Framework (modified from Cheng et al. 2016)

scenario. A scenario typically entails an associated visual perspective and associated affective state (i.e. a particular visual and affective phenomenology) as well as an associated conceptualization. The associated conceptualization in particular will be crucial for elucidating the influence of the narrative self on episodic recall, so we elaborate on conceptualization in the next subsection.

\subsection{Conceptualization of 'Actions' and 'Events'}

A recalled episode contains an answer to the question 'what happened?'. However, there is no unique answer to that question. People try to make sense of a particular action or event by narrating it (Bluck and Habermas 2000; Singer and Bluck 2001; Thorne, McLean et al., 2007; Singer et al., 2013; Cox and McAdams 2019). There is a constructive influence that we can describe in detail by considering the insights from philosophy and psychology of action.

To illustrate, consider the following examples:

To the question 'What is he doing' the answers may with equal truth and appropriateness be 'Digging', 'Gardening, 'Taking exercise', Preparing for winter' or 'Pleasing his wife' (...) [A]nother equally trivial example of a set of compatibly correct answers to the question 'What is he doing?' [could be] 'Writing a sentence'; 'Finishing his book'; 'Contributing to the debate on the theory of action'; 'Trying to get tenure'. (Macintyre 1984, pp.206-7)

Obviously, it is possible to describe a behavior in various ways. But, typically, in everyday life, agents are not concerned with these possible descriptions. 
Rather, they have a (more or less definite) sense of what they are doing. Action Identification Theory (AIT) substantiates and empirically validates this intuition (Vallacher and Wegner, 1987; 1989; 2011). Central to AIT is the idea that agents identify their actions on different levels. Relatively low levels of identification pertain to how an act is carried out (e.g. 'writing a sentence'). Relatively high levels of identification pertain to why an act is carried out (e.g. 'trying to get tenure'). As Vallacher and Wegner acknowledge, high levels of identification indicate the embeddedness of an action in the agents long-term plans, goals and indeed self-narratives.

This is a point that philosophers of action converge on as well. To determine which action is actually carried out by a particular behavior, we need to make reference to the agent's intentions (cf. Goldman 1970), and self-narratives integrate those intentions. Regarding the intentional actions in the examples he provided in the quotes above, Macintyre adds

[T] he intentions can be ordered in terms of the stretch of time to which reference is made. Each of the short-term intentions is, and can only be made, intelligible by reference to some longer-term intentions; and the characterization of the behavior in longer-term intentions can only be correct if some of the characterizations in terms of shorter-term intentions are also correct. Hence the behavior is only characterized adequately when we know what the longer and longest-term intentions invoked are and how the shorter-term intentions are related to the longer. Once again we are involved in writing a narrative history. (1984, pp.2078 , italics added)

So the point that we want to make is that the narrative self can influence episodic recall by changing the level of action identification, and it does this based on narrative concerns and other motivations (which we will discuss in Section 4.4).

This proposal also fits neatly with Construal Level Theory (CLT) (for a review of CLT, see Trope and Liberman 2010). CLT posits that when an agent increases the psychological distance between an object or event and the here-and-now (i.e. engages in either past- or future-directed mental time travel), the mental construal of this object or event becomes higher or more abstract. In terms of AIT, it is identified at a higher level. In other words, thinking about an event or action that happened long ago (or that happens far into the future) comes with a more abstract construal of that action or event, compared to thinking about something that happened recently or will happen in the near future.

To make matters more concrete, consider that the person in the Macintyre quote might remember the described episode in various ways. On the one hand he could remember it with a relatively high level of action identification, where the gist of the memory is that the episode contains "the moment I finished my book that would eventually win me an award". In that case it might be connected to a particular selfnarrative of how one became a successful academic. On the other hand, the person might remember the episode with a relatively low level of identification, where the episode contains "a memory of struggling with the dreary editorial work and checking for spelling errors". In that case, there is no connection to the self-narrative of how one became a successful academic. 
We are now at the point where we can outline the relevance of the proposed conceptualization of events as an important influence of narrative selves: The central claim is that the relevant level of conceptualizing an event that is recalled by episodic memory is determined by the narrative self and one central function of the influence of the narrative self is that the resulting conceptualized episode can be (more easily) integrated into the narrative self (if it is of sufficient importance to the self). The embedding of the conceptualization in AIT and CLT offers an empirically validated and substantiated point of departure that fits with philosophical work on narrativity (cf. Macintyre 1984). It also fits empirical work on narrativity, particularly narrative meaning-making where one narrates an event to make sense of it (cf. Thorne, McLean et al., 2007; Singer et al., 2013). Indeed agents might narrate experiences to establish self-event connections, thereby clarifying how the event relates to the person and their goals, and enabling an integration into the self-narrative (cf. Pasupathi, Mansour \& Brubaker 2007; Rubin et al. 2019).

\subsection{The Relevance of Conceptualization of Events for Memory Research and for Rebutting Strawson's Skepticism}

The relevance of our central claim is supported by the fact that CLT and AIT are also fruitfully adopted by some memory researchers to investigate the influence of narrative selves (Libby and Eibach 2011; d'Argembeau, Renaud and Van der Linden 2011). For instance, Rubin et al. (2019) acknowledge CLT in their study on 'self-narrative focus' during recall. Boucher and Scoboria (2015) refer to AIT literature in discussing what they label a 'coherence focus', which entails construing events on a more abstract level which "promotes adaptive self-reflection by affording people the cognitive means with which to reconcile transitional experiences [i.e. experiences of events that significantly impact our everyday activities and sense of self]" (p. 361).

Based on the current proposal, we advocate two revisions for existing research on episodic memory. First, we think such research should be more sensitive to different action identities or conceptualizations of events, and the terminology and frameworks of AIT and CLT are useful in this regard. Especially, we think incorporating such frameworks into Conway's SMS would be extremely fruitful to further delineate the role of narrative selves in the SMS. Let us elaborate this:

In its current form, both the revised and original SMS distinguish between general events (and lifetime periods or life-stories) and specific events (cf. Conway 2005; Conway, Justice and d'Argembeau 2019). We would highlight that in the SMS, abstract representations (e.g. general life-events) are related to abstract goals and thus require high-level identities, whereas concrete representations (e.g. specific life-events) are related to concrete goals and thus require low-level identities. That is, action hierarchies (of AIT) and goal hierarchies (of SMS) form two sides of the same coin. The role of the narrative self in these hierarchies is setting up, ordering and integrating these goals, that is, configuring the hierarchy, hereby indirectly determining the conceptualization of 
recalled events. This demonstrates a key role of the narrative self which we will exploit in our account. ${ }^{5}$

A second revision to memory research that we would advocate concerns the fact that even studies which are sensitive to different action identities, still have a simplified view towards what constitutes an 'event'. Bearing in mind the philosophy of action literature highlighted earlier and our discussion of conceptualization of episodes, we believe the following tends to be overlooked in such studies.

There may be cases where an event becomes narrated based on acts of reflective meaning-making and thereby the person may determine a particular level of conceptualization or adopt a specific action identity. Thus, we may have to distinguish the prereflexive registration and the (reflective) narration of events: the former involves an event prior to narration (with action identity or conceptualization A), while the latter is the narrated event (with action identity or conceptualization B). If you ask a person "what happened", they may initially respond by describing the pre-reflective factual states of events (low-level identity) but then add an interpretation of what that means for them (high-level identity). We have argued that under the influence of the narrative self the conceptualization may shift from A to B.

The central point here is that remembered events are more closely intertwined with the person remembering them. Colloquially put: the answer to the question "What happened?" depends on the person you ask the question to. This means that in many cases, it is not possible to disentangle the event from the person's self-narrative. Yet this seems to be presupposed by some researchers. For instance, Rubin et al. (2019) study the self-narrative focus that individuals may adopt, in which "a person steps back and views the event in the context of their overall life story" (ibid., p.63). They aim to investigate how such a self-narrative focus may differently affect a memory depending on 'event characteristics' such as valence. In doing so, they seem to imply that we can isolate the event (and its characteristics) from the self-narrative a person has. But in many cases, this may depend on the extent to which the event has already been narrated: in such cases it is the self-narrative which makes an event positive or negative in the first place. For example, not being promoted at work may be a negative event from the perspective of an 'academic' self-narrative, but may be a positive event from the perspective of a 'parental' self-narrative (assuming for the sake of the argument that being promoted would entail more overtime work). Thus, we cannot determine the valence of the episode of 'not being promoted' in isolation from the self-narrative, although this does seem to be presupposed by the study of Rubin et al. (2019).

Our claim that the narrative self may modulate memory by steering towards a particular conceptualization is not only advantageous for research on memory and mental time travel.

\footnotetext{
5 Importantly, this proposal fits with recent discussions of Conway's SMS. For instance, Grysman and Hudson (2011), similarly highlighting the importance of the narrative self in modulating memory encoding and retrieval, provide the following example: "A memory of tearing ligaments in one's leg will have different salience for a student who spends most of his time in the library than for an athlete who knows that important scouts will be at the next game. The meaning of the event is transformed based on the implications that the individual perceives" (ibid., p.502). Moreover, although they do not explicitly use the AIT/CLT frameworks, it does seem to be implicit in their analysis. In their experiment, they draw on the coding elements developed by Nelson (1998), distinguishing 'Orientations' and 'Actions' from 'Evaluations'. The former could easily be construed as low-level action identities, indicating what happened when and to whom (e.g. "people arrived at the party"), and the latter could be seen as pertaining to high-level identities, indicating why something happened (e.g. "I was happy because my friends enjoyed the party').
} 
Conceptualization of events also offers a theoretical tool that enables us to bypass Strawson's worries. Central to Strawson's skepticism is his claim that we do not "live our lives narratively". Skeptics like Strawson argue that they do not experience themselves or their lives in a narrative fashion. That there is no 'narrative quality' detectable in their phenomenology. However, we think that such skeptics are misguided in seeking a specific narrative feature in experience. In contrast, we think that there is a direct influence that selfnarratives exert, e.g. they can modify the phenomenology of an episodic recall by making experiences intelligible by triggering a conceptualization that coheres with our selfnarratives and fits our narrative concerns and long-term goals (cf. Section 4.4).

For instance, two people might experience (or recall) the same event differently, depending on their self-narrative. Using the terminology from AIT, we could point out that one person experiences the action or event with a relatively low action identity whereas the other experiences it with a relatively high action identity. Crucially, this latter person only experiences it the way she does because of her self-narrative. It is in this way that narrative affects our experience (or our memory): not by adding some specific narrative quality to it but by making it intelligible and coherent. As we will argue below, a narrated memory (e.g. where there has been a shift from a low level conceptualization to a higher level conceptualization) can have repercussions for other aspects of our psychology including modifications of the phenomenology of the recall without requiring that a narrative quality is added to the experience.

\section{How the Narrative Self Modulates Memory}

At this point we can clarify the influence of the narrative self on episodic recall. To do this, we presuppose only a rather general distinction, namely between the input, output and process of scenario construction: this enables us to delineate three corresponding routes of influence of the narrative self (cf. Figure 2). First, the narrative self may influence the output of scenario construction, by reinterpreting the associated conceptualization. Second, it may influence the process of scenario construction, by constraining and selecting relevant information. Third, it may influence the input of scenario construction, by behavioral embedding and reweighting the relevance of input. We elaborate on these three routes in Sections 4.1, 4.2 and 4.3, respectively. In Section 4.4. we address the various motivations that might drive the narrative self in modulating memory.

\subsection{Route 1. Influencing the Output of Scenario Construction: (re)Conceptualization of Scenarios and its Effect on the Phenomenology of Memory}

In Section 3.3 we already addressed the central tool of the route of reconceptualization, namely how the narrative self might change the content of memories by triggering specific levels of action identification. ${ }^{6}$ In addition to this direct influence by reconceptualization of

\footnotetext{
${ }^{6}$ One may worry whether such conceptualizations are relevant for the episodic recall at all since it could be argued that the episodic recall consists in a visual scenario only and verbal descriptions are an add-on going beyond episodic memory. This would be a view according to which memory recall is a purely bottom-up modular process independent form conceptualizations. We argue that in parallel to the claim of cognitive penetration of our perceptual experience (Macpherson 2012; Newen \& Vetter 2017), it also seems plausible to allow for a cognitive penetration of episodically recalled scenarios.
} 


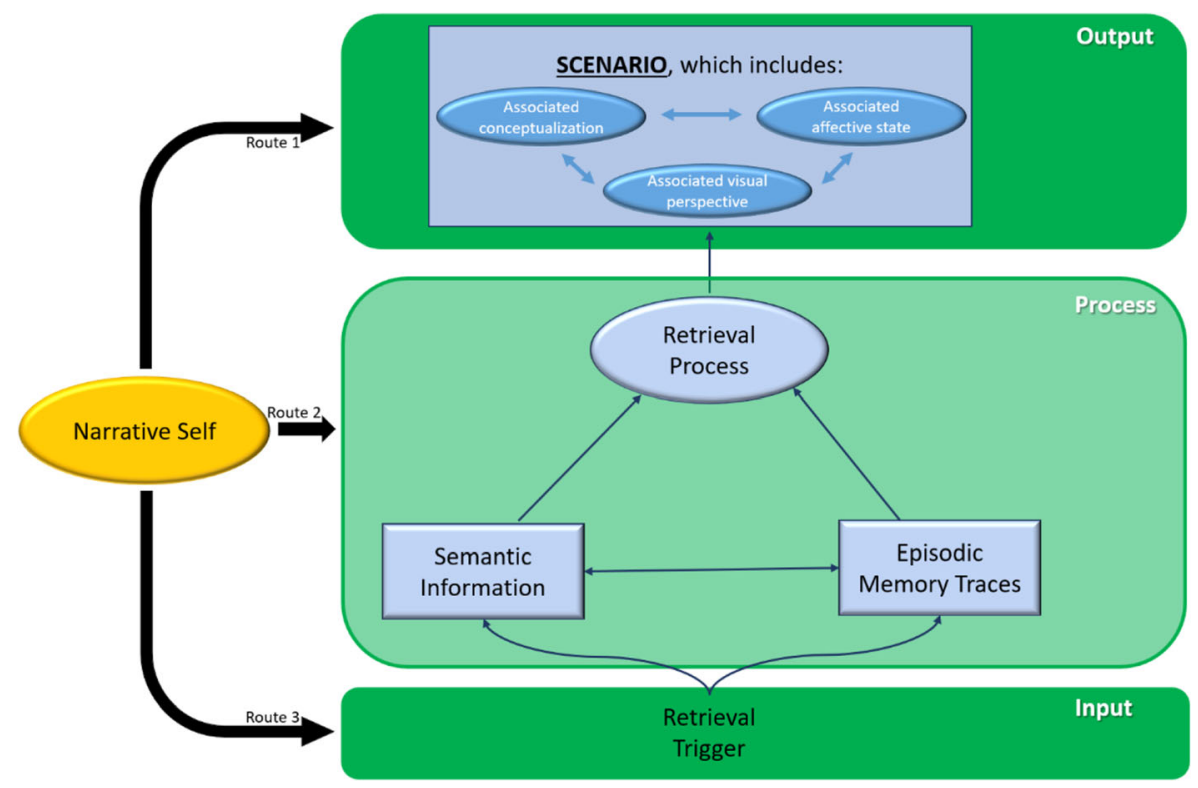

Fig. 2 A modified Scenario Construction Framework

recalled scenarios, we discuss how the narrative self might, in addition to content, also change the phenomenology of memories through the conceptualization-route. Research shows that various experiential dimensions of memory, such as those distinguished by Sutin and Robins (2007), tend to cluster together (cf. Berntsen and Bohn 2010; Cox and McAdams 2019). Here we focus on how the (re)conceptualization route leads to a particular visual perspective in memory, which in turn modulates its affective dimension (emotional intensity, sense of re-living and valence).

Regarding visual perspective, one can recall an episode from one's past in two ways. First, from a so called field perspective, where one recalls the episode from a firstperson perspective, as if one looks through one's own eyes. Second, from an observer perspective, where one sees oneself and one's surroundings, much like an observer would (Nigro and Neisser 1983; McCarroll 2018). Regarding these visual perspectives in memory, Lisa Libby has done extensive research on how field perspectives focus on the concrete details of the episode whereas observer perspectives are associated with understanding the meaning of the event and its role in one's broader life. For instance Libby, Shaeffer and Eibach (2009) elucidated the bidirectional link between visual imagery and action identification level. Across a series of studies, Libby and colleagues highlighted the interplay between visual perspectives, the construal of a recalled event, and its relation to the agent's self-concept and life-narratives. We will here discuss some of those studies and how they relate to other dimensions of our phenomenology (for a more extensive review see Libby and Eibach 2011).

To start, consider how the visual perspective in memory interacts with the emotional intensity, valence and sense of re-living of the recalled episode. Based on existing research, Berntsen and Rubin (2006) note that "memories recalled from a field perspective are generally experienced as more emotional and/or contain more information about emotional and other subjective states as compared to observer memories" (ibid., 
p.1195). Moreover, negatively valenced episodes, such as traumatic experiences, are more often recalled from an observer perspective. Based on their own study, Berntsen and Rubin (2006) point out that "changing perspective from field to observer was consistently associated with reduced reliving qualities, whereas changing from observer to field did not lead to the reverse increase in memory qualities" (ibid., p.1206). They conclude that "observer perspective is associated with a reduction of emotional and sensory reliving of autobiographical memories" (ibid., p.1211).

The Narrative Self May Influence the Emotional Intensity of Episodic Recall However, Valenti et al. (2011) showed that this might be a simplified view, as relevance to the self seems to also play a role. To investigate this, they conducted a clever study focusing on regretful memories for things that people did or did not do. The idea behind the study is that regrettable actions are experienced as painful, but inactions are only experienced as painful when one considers the consequences of that inaction for one's life as a whole. So painful regretful inactions are typically construed at a higher level than painful regrettable actions which focus on the details of what one did. The authors found that there is more felt regret for inaction when adopting an observer perspective as opposed to a field perspective. So emotional intensity is dependent not only on the perspective but also on how the episode fits (or in this case, does not fit) in one's self-narrative. Valenti, Libby and Eibach (2011, p.736) further highlight that regret also increased when the original event was experienced unemotionally but was "infused" with emotion during recall, which points towards the modulating role that narrating a recalled event can have. Indeed Cox and McAdams (2019) emphasize that in an observer perspective "the narrator steps out of the time frame of the original experience and makes global or more general reflections" (ibid., p.134).

Incompatibility of Memorized Events Concerning the Narrative Self Interacts with Perspectivity Libby and Eibach (2002) found that the (in)compatibility with one's self-concept affects what visual perspective is adopted. Specifically they found that an observer perspective is adopted when the episode is incongruent with one's selfconcept. Conversely, Libby, Eibach and Gilovich (2005) showed that the adopted visual perspective also affects judgments of changes of the narrative self. In a series of studies they found that if an agent focuses on differences between the current self and past self then adopting an observer perspective will lead to a judgment of more selfchange. In contrast, if the agent is focusing on similarities then adopting an observer perspective will lead to a judgment of less self-change.

Focusing on the narrative self reduces the intensity of imagery and reliving of an episodic recall: As CLT would predict, the psychological distance one experiences in a recalled episode is related to the intensity of imagery in reliving an experience (Trope and Liberman 2010. See also Wilson and Ross 2003). In an encompassing study that investigated not only past episodes but future projections as well, Berntsen and Bohn (2010) found a modulating role for narrative. In their own words:

We identified two different dimensions in episodic remembering and episodic future thinking that showed a similar pattern across all four past and future event 
categories. One was imagery, referring to sensory imagery and a subjective feeling of reliving (or preliving) the event. The other was self-narrative, referring to how personally important and central to the life story and identity the remembered or imagined event was considered to be. Consistently across all four event categories, imagery dropped with increasing distance to the present, whereas selfnarrative increased with increasing temporal distance to the present. (Berntsen and Bohn 2010, p.275)

They conclude that "life scripts [i.e. self-narratives] play an important role for providing structure and meaning to the narrative understanding of our personal past, as well as our personal future" (ibid. See also Grysman and Hudson 2011).

In sum, the discussed research fits the proposal that narrative selves modulate the conceptualization (high or low) of an event or action, which impacts the content and also the phenomenology of memories (specifically their visual perspective, degree of affectivity and felt distance of the memory).

\subsection{Route 2. Influencing the Process of Scenario Construction: Constraining and Selecting (Semantic) Information by Conceptualization of Scenario Components}

According to our proposal, 'what happened' during an episode may depend on the conceptualization of the recalled event (which in turn was determined by the narrative self). We hypothesize that in the reconstructive process of memory retrieval, different scenario components (such as the gist of an episode and the potentially relevant semantic information that may be used to enrich this gist) may also be affected by how the scenario was conceptualized.

To see why this may be the case, consider the following example from the CLT literature:

[B]y moving from representing an object as a 'cellular phone' to representing it as 'a communication device', we omit information about size; moving from representing an activity as 'playing ball' to representing it as 'having fun', we omit the ball. Concrete representations typically lend themselves to multiple abstractions [which are] selected according to its relevance to one's goals. Thus, if one's goal is to contact a friend, then 'a communication device' is relevant, but size is not" (Trope and Liberman 2010, p.2)

Given the novelty of our proposed reconceptualization of scenario components being influenced by narrative selves (emphasizing construal by conceptualization), there is no direct evidence for this hypothesis in existing literature, because no existing studies adopt the same view of narrative selfhood. ${ }^{7}$ Nevertheless, there is ample evidence that may serve to indirectly substantiate our claim. We summarize such evidence in this subsection.

\footnotetext{
${ }^{7}$ To illustrate, the effects of activating self-concepts or self-image on memory accessibility have often been investigated (Wang 2008; Rathbone and Moulin 2017), but these authors do not employ a narrative selfconcept, let alone one that explicitly takes into account different conceptualizations of events.
} 
The Conceptualization of an Event or Event Component Constrains the Informational Contents Going into the Scenario Construction Process To illustrate, if the event of one's marriage is recalled with a high-level identity, the resulting content might be e.g. "the day two families became one", whereas a more low-level identity might lead to the gist being e.g. "walking down the aisle". In the former case the gist of the memory may be enriched by semantic information about family members, whereas in the latter case semantic information about the wedding venue may be added, leading to different memory contents.

The constraining of semantic information is mainly important for generative retrieval processes. These are distinguished in Conway's Self-Memory System from direct retrieval processes. Both processes try to access the event-specific autobiographical knowledge base (Conway 2005). However, whereas direct retrieval is sparked by a cue which triggers direct access to this knowledge base (and thus requires no effortful search), generative retrieval is a more 'top-down' process where there is a goal-directed search in the knowledge base for a particular memory. It is a more effortful and deliberate process, guided by associative effects: various cues can trigger one another until the memory which fits the goal at stake is found. Importantly, in generative retrieval there is more need for semantic information to be added to the process to guide the retrieval of the specific memory (Uzer, Lee and Brown 2012; Addis et al. 2012). Crucially, the semantic information provided by self-narratives plays a modulating role in generative retrieval (Conway 2005; Berntsen 2010). This has subsequent effects: whether a memory is retrieved in a direct or generative process may affect its characteristics, such as its associated visual perspective (Harris, O’Conner and Sutton 2015).

If the construal of the episode alters how the scenario is constructed (e.g. in terms of which informational contents are processed), then one prediction would be that a negative construal, where the core information contains an action identity that is threatening to the self, is processed differently from a positive construal (in terms of how much or which semantic information is added to the core information). Prima facie, the mnemic neglect model (MN-model, e.g. Sedikides and Green 2009) seems to provide evidence which points in that direction. According to the $\mathrm{MN}$-model, memories that contain information that is threatening to central self-conceptions (but not peripheral self-conceptions) are recalled less, indicating retrieval selectivity. The $\mathrm{MN}$ model suggests that this happens through allocating less processing resources to negative information that is threatening to central self-conceptions. More specifically, it suggests that such threatening information remains on what they call 'Stage 1' processing where it is compared to stored semantic (self-)knowledge. Only nonthreatening information continues to 'Stage 2' for more elaborate processing. An important caveat is that the MN-model conceptualizes the self in terms of either selfconceptions or traits, and not narratives. However, it is not unlikely that semantic selfknowledge regarding especially central self-conceptions take a narrative form. Or that the central self-conceptions (which do not take a narrative form) may be mainly determined by the self-narratives (Singer et al. 2013).

The Conceptualization of an Event Affects the Relevance and Accessibility of Information in Scenario Construction On the one hand, we can look at short-term accessibility of information. A study by Dumont, Sarlet and Dardenne (2010) indicated how a particular construal of an event modulates its accessibility. Similar to the current 
proposal, Dumont et al. highlight the interrelation between construal and self-conception, and how this relation affects memory retrieval. In this particular study, the researchers showed that when women were confronted with the stereotype of women being less competent than men, this affected their self-construal to the extent that they felt less competent which led to memories of being incompetent to become more accessible.

Modulating short-term accessibility can also happen indirectly (and perhaps unintentionally) by regulating one's emotional states. This forms the core of a recent proposal by Pascuzzi and Smorthi (2017), who suggest this indirect link. First, autobiographical narratives contribute to emotion regulation, for instance by changing the construal of an event or embedding it in a self-narrative. Subsequently, the emotional state of the agent, i.e. the endresult of their emotion regulation, may affect memory retrieval and encoding.

Another line of evidence comes from research on the self-reference effect. Roughly, this effect entails that information that is self-relevant is processed differently than nonself-relevant information. Typically, self-relevant information is processed more elaborately - an effect which has also been found in memory (see Symons and Johnson 1997 for an overview). However, it is not entirely clear to what extent the 'self' at stake in this effect is a narrative self (cf. Klein 2012). There are studies suggesting that it is, but these may not be deemed decisive. For instance, Carson, Murphy, Moscovitch and Rosenbaum (2016) found that narrative information may contribute to the selfreference effect. Moreover, both the self-reference effect as well as self-narratives are considered as key integrative components in cognitive systems (Conway, Singer and Tagini 2004; Sui and Humphreys 2015; Sui 2016). In this sense, it may be that selfreference serves integration over a shorter time scale, and self-narratives allow for integration over a longer time scale (Conway 2005; Gallagher and Daly, 2018; Newen 2018). The relevant point is that the relevance of information for the self and especially also for the narrative self influences the type of cognitive processing.

On the other hand, the narrative self (through reconceptualization of events) may affect the long-term accessibility of information during scenario construction. For instance, consider the well-documented 'reminiscence bump', i.e. the phenomenon that people have an increased recollection for events that took place during adolescence or early adulthood. It is often thought that the increased accessibility and ease of recall for memories in this period has to do with the fact that these memories play a pivotal role in one's self-narrative (Fitzgerald 1998; Rathbone et al., 2008). That is, these autobiographical memories play a role in constructing key attitudes and feelings of the selfmodel during the well-known period of discovering one's own identity by becoming an adult.

The Narrative Self and Reconceptualization May Help to Elucidate the Phenomenon of Semantization This phenomenon involves that over time, episodic memories may be transformed into semantic memories. Our proposal regarding the narrative self and its influence on reconceptualizing events may help to better understand semantization and its driving force. First, consider the recent neuroimaging study by Linde-Domingo, Treder, Kerrém and Wimber (2019). They found that in reconstructing a memory the flow of information is reversed: when perceiving an object and encoding the episode with the object, low-level perceptual features are processed faster and earlier than high- 
level conceptual features. But during associative memory recall, conceptual information is reconstructed more rapidly than perceptual details. If semantic information is prioritized during retrieval then this highlights the importance of the narrative self as high-level (abstracted) conceptualizations may be the result of the modulating role of the narrative self. An argument in favor of this view comes from the integrative function of the narrative self. As Conway, Singer and Tagini (2004) emphasized, long-term memories may be biased towards coherence (i.e. what does an event mean to me, my life, my narrative) at the expense of accuracy (i.e. what factually happened). ${ }^{8}$ Crucially, the narrative self is the main tool for establishing coherence in long-term memory and it steers towards high-level conceptualizations (as opposed to low-level conceptualizations) for this task of integration.

So far, we have discussed indirect evidence for the influence of conceptualization on the process of constructing a scenario including scenario components. We are aware that this is only one of many important aspects of processes which constitute scenario construction: concerning this multifactorial process there remain many open questions which we cannot clarify in this article, some of which go beyond our focus on the role of the narrative self, e.g. do changes in a self-narrative transform existing memory traces? Or are new traces formed? And if so, what happens to the old traces over time? Although many details of semantization are still being investigated and debated, we can rely on it as an important subprocess of scenario construction and it is intensely constraint by the narrative self.

\subsection{Route 3. Influencing the Input of Scenario Construction by Behavioral Embedding and Reweighting its Relevance}

A third route through which the narrative self modulates memory relies on two strategies for modulating the input of scenario construction. Central to these strategies is that the narrative self might influence whether and to what extent environmental information serves as a retrieval trigger. ${ }^{9}$ As such, it highlights that memory is tightly interwoven with action (Glenberg 1997; Bluck, Alea and Mroz 2019). Thus, we want to argue that another influence of the narrative self is to alter the environment by organizing the epistemic accessibility and relevance of objects as cues such that it provides cues to memories that fit narrative concerns (e.g. self-enhancement or coherence). Let us elaborate on the two complementary strategies.

First, the strategy of behavioral embedding entails that the narrative self may modulate the accessibility and availability of cues. This is done through acts of scaffolding and niche-construction. There has been ample research on the distributed character of our cognition and how our environment might scaffold our memory (for a discussion and overview see Michaelian and Sutton 2013). Most of this research

\footnotetext{
${ }^{8}$ At the same time, there is also evidence that narrative organization of information at encoding actually improves the accuracy of long-term retrieval (cf. Wang, Bui and Song 2015).

${ }^{9} \mathrm{We}$ focus on the material scaffolding of our memory (to supplement the much more studied social scaffolding, cf. Pasupathi 2001; Nelson and Fivush 2004). Emphasizing material scaffolding is important for Strawson $(2018$, p.27) as well, as he seems to suggest that it is the constancy of one's environment and what one is doing that may provide a sense of continuous self-experience (rather than diachronic selfconsciousness).
} 
focuses on short-term or semantic memory, but it has recently been argued that narrative selves and autobiographical memory are similarly distributed (see e.g. Breen et al. 2017; Heersmink 2017, 2018; Dings 2019). For instance, many objects such as pictures, diaries, souvenirs, jewelry, books or social media profiles may serve important functions in our self-narrative. On the one hand such objects may be experienced as part of the self (cf. Gallagher 2013 on 'extended' self-aspects). On the other hand, they may fulfil an 'evocative' function (Heersmink 2018). That is, objects may evoke particular autobiographical memories. Many of these are integrated into our daily lives such that, according to Heersmink (2018), it is fair to say that we are dependent on those objects to recall particular memories. Here we argue, in line with e.g. Heersmink (2018), that the narrative self can play an important role in managing which object and environmental cues are present, by constructing or seeking an environment that 'fits' our narrative (Breen et al. 2017; Dings 2019). This seems particularly the case for people who suffer from pathologies that affect their memory, such as dementia (Heersmink 2017). But it might also be the case more generally, as not being able to engage with particular parts of one's environment may reduce the agent's opportunities for 'situated episodic simulations' (as Caravá 2020 recently suggested).

A second strategy in which the narrative self influences the input of scenario construction and thereby modulates the Self-Memory System is to alter the relevance of cues (as opposed to making them available or more accessible). More specifically, the narrative self may change their narrative meaning. By changing what an object means to the person, those objects may evoke particular memories or behavior that fits the narrative concerns of that person. The idea that memory contributes to changes in relevance and meaning was also proposed by Glenberg (1997). He argued that for any agent interacting with its environment, it is required to differentiate between objects. To use Glenberg's example: there are many paths that afford taking, but you might require a particular path (e.g. the path home). Such differentiation then consists in clarifying the relevance of an object and what it affords to you. According to Glenberg, experiences of our environment and what it affords are combined (or 'meshed' as he calls it) with e.g. memories of past interactions with that object. As such, "the path becomes the path home and the cup becomes my cup" (Glenberg 1997, p.4).

The current proposal would go a step further in emphasizing how narrative selves might change the meaning of an object. As we have elaborated in previous work, narrative deliberation may help to change whether and when an object is experienced as relevant, thereby directly affecting our agency (Dings 2018, 2020). There we argued that construing an object as affording a particular action, under the influence of narrative concerns, may alter what that object means and, subsequently, affords (Dings 2020). Regarding memory, we would argue that it is not only memories as such which modulate the relevance of an object (as Glenberg suggested), but narrated memories, with a particular conceptualization of the event and the objects in that event.

\subsection{Motivations}

After clarifying how the narrative self may modulate episodic recall (Sections 4.1-4.3), we now want to discuss why the narrative self modulates episodic memory (either consciously or unconsciously). 
It is generally acknowledged that what memory is for may affect e.g. encoding and retrieval. As Bluck, Alea and Mroz (2019) recently put it, "form follows function". Regarding the various motivations that can guide our memory, Bluck (2003) helpfully distinguished between three functions of autobiographical memory in everyday life: the self-function, social function and directive function. The latter has to do with guiding our actions and enabling our future agency. The social function of autobiographical memory pertains to sharing memories and enabling us to empathize with others. Regarding the self-function, we can think of establishing and maintaining a sense of self-continuity, but we can also think of issues of self-esteem, distinctiveness, belonging, efficacy and meaning.

What is pivotal is the distinction between short-term and long-term motivations of the agent. As Conway, Singer and Tagini (2004, p.491) rightfully noted, in memory there may exist a tension between "adaptive correspondence (experience-near sensoryperceptual records of goal activity) and self-coherence (a more abstracted and conceptually-rich long-term store of conceptual and remembered knowledge)". In other words, sometimes our memories are geared towards representing a correspondence to what factually happened whereas at other times our memory is geared towards representing an interpretation of what happened such as to cohere with, in particular, our self-narrative (Conway, Singer and Tagini 2004; Bluck 2003; Bluck and Habermas, 2000). As we can see from the quote by Conway, Singer and Tagini, which of these motivations is at play has an effect on the construal of the episode (in terms of low-level identities or abtract high-level identities).

Moreover, the trade-off between correspondence and coherence in the case of narrative selves adds an additional layer of complexity to the issue of self-enhancement. Indeed there is plenty of research which indicates that people are selective in their memory retrieval such as to recollect memories that enhance their self-image (Wilson and Ross 2003; Alicke and Sedikides 2009). In this respect, Sedikides and Green (2009) call memory a 'self-protective mechanism'. This means that in the case of altering a memory such as to cohere with a self-narrative, there are several motivational options on the table. Because a coherent self-narrative is, presumably, a better selfnarrative than an incoherent one, simply striving for coherence can also be seen as a form of self-enhancement. We could call this a weak form of self-enhancement and contrast it with strong forms of self-enhancement where the agent's primary motivation is not coherence but to self-deceive (Michel \& Newen 2010).

For present purposes, what concerns us is the finding that all these authors converge on, is that what the agent is doing (e.g. seeking coherence versus self-enhancing) affects which memories are retrieved and how they are retrieved. In this process, selfnarratives play a modulating role. For instance, high points and low points in one's life-story are processed differently (Cox and McAdams 2019). Indeed making the self salient during retrieval steers people towards interpreting the broader meaning of events, that is, to clarify how this event coheres with their current sense of self and other memories (Grysman and Hudson 2011).

\section{Predictions}

Our account suggests the following predictions. First, we would expect levels of personal agency (PA) to affect memory encoding and retrieval. Within the AIT 
framework, PA "represents the degree to which an individual has organized his or her actions into abstract, meaningful categories that can channel behavior into dispositional tendencies" (Vallacher and Wegner 2011, p.338). They suggest that, like personality traits, PA is predictive of particular behavior and cognitive characteristics (Vallacher and Wegner 1989). Thus, we would expect significant differences in memory encoding and retrieval between people who score high versus people who score low on a PA scale. We hypothesize that incorporating PA scales into memory research may contribute to disentangling the mess surrounding 'individual differences' in memory research (cf. Section 2, see also Rubin et al. 2019 for a similar suggestion).

Second, it would be interesting to investigate to what extent memories and future simulations are interdependent by sharing or transfering levels of conceptualizations. Here would be a way to study this. First, the individual reports an episodic memory which has a low-level identity (e.g. last year I went on holiday to Spain). Then, the individual is asked to engage in future simulation regarding a similar/related topic (e.g. I will be visiting Thailand in 2025). For this task she is offered relevant information (e.g. facts about Thailand, pictures, etc) that may be used in scenario construction. The experimenter should then steer the individual towards adopting a higher-level identity for the future simulation (e.g. in this case by asking whether the individual thinks that travelling contributes to his intellectual development or long-term goals or values concerning climate change). After some time, when the individual is asked to recall the past episode again, has the memory also shifted towards a higher level identity? We think this is likely.

Third, we would predict self-defining memories to have higher levels of construal. Surprisingly, this topic has not been received any thorough investigation (but see Singer et al. 2013). There are some studies providing evidence which seems to point in this direction: Wood and Conway (2006) found that high subjective impact of a selfdefining memory was related to more meaning-making. Although they do not explicitly endorse the CLT/AIT terminology (which is something that we have argued for that they should), they do frame meaning-making in terms of clarifying 'why' something happened and 'stepping back from the event' (which would fit the high-level construal of events). In addition, Demblon and d'Argembeau (2017, p.8) explain one of their somewhat unexpected findings by suggesting that "when processing self-defining initiating events, participants might have focused on event properties that make them central to their sense of identity (such as their implications, meaning, or underlying goals)". This could easily be reformulated in terms of high level action identities or high level construal. Finally, Boucher and Scoboria (2015) investigate the effects of adopting a 'coherence focus' (i.e. a higher construal or conceptualization which emphasizes embeddedness in a self-narrative) on 'transitional events', which are events that are pivotal to how people understand themselves and the world.

\section{Conclusion}

We have aimed to clarify the modulatory role of narrative selves in episodic memory processes. At the center of our proposal is the acknowledgement that any behaviour or event can be described on various levels. We adopted terminology from AIT and CLT to provide a taxonomy of descriptions: low-level identities or construals convey the 
details of an event or behaviour (i.e. a factual description of what happened, when it happened and to whom it happened) and high-level identities or construals convey a meaningful embedding of an event or behavour into a wider context, including the individual's self-narrative (i.e. why something happened). The fact that narrative selves may modulate the construction of the past by altering the action identity of an event was foregrounded by our proposal. Starting with this observation we distinguish three routes of influences of the narrative self on episodic recall, namely by influencing the output, the process and the input of scenario construction: Route 1 is the influence on the output of scenario construction with 'construal by conceptualization': this can modify the focus and content of a scenario but also the phenomenology of the experienced recall. Route 2 consists in influencing the process of scenario construction by constraining and selecting (semantic) information. This is due to the conceptualization of scenario components. Finally, route 3 consists in influencing the input of scenario construction with two strategies in dealing with memory cues, namely behavioral embedding which includes e.g. an active avoidance of cues triggering undesired memories and the reweighting of the relevance of activated cues triggering a recall. We outlined how this route enables the narrative self to modify the availability, accessibility and relevance of ecological information through niche-construction and meaning-making.

This proposal has several advantages. First, by providing a framework that outlines the modulatory role of narrative selves in memory processes, it shows the importance of narrative selves in cognitive systems, pace skeptical theorists such as Strawson (2004) and Metzinger (2003). Second, it has the strength of allowing for integration between various fields of inquiry. That is, the proposed roles of the narrative selves with the three routes fits well with research on memory, mental time travel and narrative identity and it allows us to pose new questions for further systematic studies of these phenomena. Third, its clarification of the exact influences of narrative selves on episodic memory may be used by accounts which have suggested that self-narratives may help us to understand individual differences in memory and mental time travel (Bouizegarene and Philippe 2016; Rubin et al. 2019; Berntsen, Hoyle \& Rubin 2019). An application of the currently developed framework to that empirical research, unfortunately, goes beyond the scope of the current paper Fourth, this framework also allows us to shed light on the interrelation of various kinds of memory. For instance, procedural memory and declarative memory seem to be related in various ways (see e.g. Christensen, Sutton and Bicknell 2019). On the current proposal, declarative narrative knowledge, through meaning-making, interacts with bodily and habitual abilities anchored in procedural memory, which in turn is related to prospective memory. Fifth, consider the distinction between voluntary and involuntary memories. Roughly, the former may be the result of a generative retrieval process, whereas the latter simply 'pops up' or comes to mind without any clear reason (see Berntsen, 2010 for a discussion). However, our discussion of Route 3 suggests that we might further distinguish between 'direct' and 'indirect' voluntary memories. The latter involves cases where we have actively shaped our environment such that it is filled with cues that may automatically trigger a specific memory.

In a nutshell we offer a theoretical framework that allows us to account for three types of systematic influences of the narrative self on episodic recall and furthermore, this framework has the potential to be fruitfully integrated into a general theory of memory. 
Acknowledgements Gefördert durch die Deutsche Forschungsgemeinschaft (DFG) - 419046236 (DFG Forschungsgruppe FOR2812 'Szenarien der Vergangenheit'); Funded by the Deutsche Forschungsgemeinschaft (DFG, German Research Foundation) - 419046236 (DFG Research Unit FOR2812 'Constructing scenario's of the past').

Funding Open Access funding enabled and organized by Projekt DEAL.

Open Access This article is licensed under a Creative Commons Attribution 4.0 International License, which permits use, sharing, adaptation, distribution and reproduction in any medium or format, as long as you give appropriate credit to the original author(s) and the source, provide a link to the Creative Commons licence, and indicate if changes were made. The images or other third party material in this article are included in the article's Creative Commons licence, unless indicated otherwise in a credit line to the material. If material is not included in the article's Creative Commons licence and your intended use is not permitted by statutory regulation or exceeds the permitted use, you will need to obtain permission directly from the copyright holder. To view a copy of this licence, visit http://creativecommons.org/licenses/by/4.0/.

\section{References}

Addis, Donna Rose, et al. 2012. Routes to the past: neural substrates of direct and generative autobiographical memory retrieval. Neuroimage 59.3: 2908-2922.

Alicke, Mark D., and Constantine Sedikides. 2009. Self-enhancement and self-protection: What they are and what they do. European Review of Social Psychology 20: 1-48. https://doi.org/10.1080/ 10463280802613866.

Bermúdez, José Luis. 2000. The paradox of self-consciousness. MIT Press.

Berntsen, Dorthe. 2010. The unbidden past: Involuntary autobiographical memories as a basic mode of remembering. Current Directions in Psychological Science 19.3: 138-142.

Berntsen, Dorthe, and Annette Bohn. 2010. Remembering and forecasting: The relation between autobiographical memory and episodic future thinking. Memory \& Cognition 38: 265-278. https://doi.org/10. 3758/MC.38.3.265.

Berntsen, Dorthe, and David C. Rubin. 2006. Emotion and vantage point in autobiographical memory. Cognition and Emotion 20.8: 1193-1215.

Berntsen, Dorthe, Rick H. Hoyle, and David C. Rubin. 2019. The autobiographical recollection test (ART): A measure of individual differences in autobiographical memory. Journal of Applied Research in Memory and Cognition 8: 305-318. https://doi.org/10.1016/j.jarmac.2019.06.005.

Bluck, Susan. 2003. Autobiographical memory: Exploring its functions in everyday life. Memory (Hove, England) 11: 113-123. https://doi.org/10.1080/741938206.

Bluck, Susan, Nicole Alea, and Emily L. Mroz. 2019. Form follows function: Autobiographical memory in ecological context. In The organization and structure of autobiographical memory, ed. John H. Mace, 93-110. Oxford University Press. https://doi.org/10.1093/oso/9780198784845.003.0006.

Bluck, Susan, and Tilmann Habermas. 2000. The life story schema. Motivation and Emotion 24: 121-147. https://oi.org/10.1023/A:1005615331901.

Boucher, Chantal M., and Alan Scoboria. 2015. Reappraising past and future transitional events: The effects of mental focus on present perceptions of personal impact and self-relevance. Journal of Personality 83: 361-375. https://doi.org/10.1111/jopy.12109.

Bouizegarene, Nabil, and Frederick L. Philippe. 2016. Episodic memories as building blocks of identity processing styles and life domains satisfaction: Examining need satisfaction and need for cognitive closure in memories. Memory 24: 616-628. https://doi.org/10.1080/09658211.2015.1034138.

Breen, Andrea V., Kate C. McLean, Kristen Cairney, and Dan P. McAdams. 2017. Movies, books, and identity: Exploring the narrative ecology of the self. Qualitative Psychology 4: 243-259. https://doi.org/ 10.1037/qup0000059.

Caravà, Marta. 2020. An exploration into enactive forms of forgetting. Phenomenology and the Cognitive Sciences Advanced online publication. https://oi.org/10.1007/s11097-020-09670-6.

Carson, Nicole, Kelly J. Murphy, Morris Moscovitch, and R. Shayna Rosenbaum. 2016. Older adults show a self-reference effect for narrative information. Memory 24: 1157-1172. https://doi.org/10.1080/ 09658211.2015.1080277. 
Cheng, Sen, and Markus Werning. 2016. What is episodic memory if it is a natural kind? Synthese 193: 13451385. https://doi.org/10.1007/s11229-014-0628-6.

Cheng, Sen, Markus Werning, and Thomas Suddendorf. 2016. Dissociating memory traces and scenario construction in mental time travel. Neuroscience and Biobehavioral Reviews 60: 82-89. https://doi.org/ 10.1016/j.neubiorev.2015.11.011.

Christensen, Wayne, John Sutton, and Kath Bicknell. 2019. Memory systems and the control of skilled action. Philosophical Psychology 32: 692-718. https://doi.org/10.1080/09515089.2019.1607279.

Conway, Martin A. 2005. Memory and the self. Journal of Memory and Language 53: 594-628. https://doi. org/10.1016/j.jml.2005.08.005.

Conway, Martin A., Lucy V. Justice, and Arnaud D'Argembeau. 2019. The self-memory system revisited: Past, present, and future. In The organization and structure of autobiographical memory, ed. John $\mathrm{H}$. Mace, 28-51. Oxford University Press. https://doi.org/10.1093/oso/9780198784845.003.0003.

Conway, Martin A., and Christopher W. Pleydell-Pearce. 2000. The construction of autobiographical memories in the self-memory system. Psychological review 107.2: 261.

Conway, Martin A., Jefferson A. Singer, and Angela Tagini. 2004. The self and autobiographical memory: Correspondence and coherence. Social Cognition 22: 491-529. https://doi.org/10.1521/soco.22.5.491. 50768.

Cox, Keith S., and Dan P. McAdams. 2019. Mean level differences in the vividness, meaning, and coherence of life story high and low points: How Valenced life stories do and do not differ. Identity 19: 128-143. https://doi.org/10.1080/15283488.2019.1604347.

D’Argembeau, Arnaud, Claudia Lardi, and Martial Van der Linden. 2012. Self-defining future projections: Exploring the identity function of thinking about the future. Memory 20: 110-120. https://doi.org/10. 1080/09658211.2011.647697.

D’Argembeau, Arnaud, Olivier Renaud, and Martial Van der Linden. 2011. Frequency, characteristics and functions of future-oriented thoughts in daily life. Applied Cognitive Psychology 25: 96-103. https://doi. org/10.1002/acp.1647.

Demblon, Julie, and Arnaud D'Argembeau. 2017. Contribution of past and future self-defining event networks to personal identity. Memory 25: 656-665. https://doi.org/10.1080/09658211.2016.1205095.

Dennett, Daniel C. 1993. Consciousness explained. Penguin uk.

Dings, Roy. 2018. Understanding phenomenological differences in how affordances solicit action. An exploration. Phenomenology and the Cognitive Sciences 17: 681-699. https://doi.org/10.1007/s11097017-9534-7.

Dings, Roy. 2019. The dynamic and recursive interplay of embodiment and narrative identity. Philosophical Psychology 32: 186-210. https://doi.org/10.1080/09515089.2018.1548698.

Dings, Roy. 2020. Meaningful affordances. Synthese Advanced online publication. https://doi.org/10.1007/ s11229-020-02864-0.

Dumont, Muriel, Marie Sarlet, and Benoit Dardenne. 2010. Be too kind to a woman, she'll feel incompetent: Benevolent sexism shifts self-construal and autobiographical memories toward incompetence. Sex Roles 62.7-8: 545-553.

Ernst, Alexandra, and Clare J. Rathbone. 2019. The role of the self in the Organization of Memories and Imagined Future Events. In The organization and structure of autobiographical memory, ed. John H. Mace, 134-159. Oxford University Press. https://doi.org/10.1093/oso/9780198784845.003.0008.

Gallagher, Shaun. 2013. A pattern theory of self. Frontiers in Human Neuroscience 7: 443. https://doi.org/10. 3389/fnhum.2013.00443.

Gallagher, Shaun, and Anya Daly. 2018. Dynamical relations in the self-pattern. Frontiers in Psychology 9: 664. https://doi.org/10.3389/fpsyg.2018.00664.

Glenberg, Arthur M. 1997. What memory is for. Behavioral and Brain Sciences 20: 1-19. https://doi.org/10. 1017/S0140525X97000010.

Grysman, Azriel, and Judith A. Hudson. 2011. The self in autobiographical memory: Effects of self-salience on narrative content and structure. Memory 19: 501-513. https://doi.org/10.1080/09658211.2011.590502.

Grysman, Azriel, Janani Prabhakar, Stephanie M. Anglin, and Judith A. Hudson. 2013. The time travelling self: Comparing self and other in narratives of past and future events. Consciousness and Cognition 22: 742-755. https://doi.org/10.1016/j.concog.2013.04.010.

Hardt, Rosa. 2018. Storytelling agents: Why narrative rather than mental time travel is fundamental. Phenomenology and the Cognitive Sciences 17: 535-554. https://doi.org/10.1007/s11097-017-9530-2.

Harris, Celia B., Akira R. O’Connor, and John Sutton. 2015. Cue generation and memory construction in direct and generative autobiographical memory retrieval. Consciousness and Cognition 33: 204-216.

Hassabis, Demis, and Eleanor A. Maguire. 2007. Deconstructing episodic memory with construction. Trends in Cognitive Sciences 11: 299-306. https://doi.org/10.1016/j.tics.2007.05.001. 
Heersmink, Richard. 2017. Distributed selves: Personal identity and extended memory systems. Synthese 194: 3135-3151. https://doi.org/10.1007/s11229-016-1102-4.

Heersmink, Richard. 2018. The narrative self, distributed memory, and evocative objects. Philosophical Studies 175: 1829-1849. https://doi.org/10.1007/s11098-017-0935-0.

Hutto, Daniel D., and Patrick McGivern. 2016. Updating the story of mental time travel: Narrating and engaging with our possible pasts and futures. In time and the philosophy of action, ed. Roman Altshuler and Michael J. Sigrist, 1st ed. New York: Routledge. https://doi.org/10.4324/9781315819303.

Klein, Stanley B. 2012. Self, memory, and the self-reference effect: An examination of conceptual and methodological issues. Personality and Social Psychology Review 16: 283-300. https://doi.org/10. $1177 / 1088868311434214$.

Libby, Lisa K., and Richard P. Eibach. 2002. Looking back in time: Self-concept change affects visual perspective in autobiographical memory. Journal of Personality and Social Psychology 82: 167-179.

Libby, Lisa K., and Richard P. Eibach. 2011. Visual perspective in mental imagery: A representational tool that functions in judgment, emotion, and self-insight. In , 44:185-245. Advances in Experimental Social Psychology. Academic Press. https://doi.org/10.1016/B978-0-12-385522-0.00004-4.

Libby, Lisa K., Richard P. Eibach, and Thomas Gilovich. 2005. Here's looking at me: The effect of memory perspective on assessments of personal change. Journal of Personality and Social Psychology 88: 50-62. https://doi.org/10.1037/0022-3514.88.1.50.

Libby, Lisa K., Eric M. Shaeffer, and Richard P. Eibach. 2009. Seeing meaning in action: A bidirectional link between visual perspective and action identification level. Journal of Experimental Psychology: General 138: 503-516. https://doi.org/10.1037/a0016795.

Linde-Domingo, Juan, et al. 2019. Evidence that neural information flow is reversed between object perception and object reconstruction from memory. Nature communications 10.1: 1-13.

MacIntyre, Alisdair (1981/2013). After virtue. A\&C Black.

Macpherson, Fiona. 2012. Cognitive penetration of colour experience: Rethinking the issue in light of an indirect mechanism. Philosophy and Phenomenological Research 84: 24-62. https://doi.org/10.1111/j. 1933-1592.2010.00481.x.

McCarroll, Christopher Jude. 2018. Remembering from the outside: Personal memory and the perspectival mind. New York: Oxford University Press.

McLean, Kate C., Monisha Pasupathi, and Jennifer L. Pals. 2007. Selves creating stories creating selves: A process model of self-development. Personality and Social Psychology Review 11: 262-278. https://doi. org/10.1177/1088868307301034.

Metzinger, Thomas. 2003. Being no one: The self-model theory of subjectivity. Cambridge: MIT Press.

Michaelian, Kourken. 2016. Mental time travel: Episodic memory and our knowledge of the personal past. Life and mind: Philosophical issues in biology and psychology. Cambridge, Mass: MIT Press.

Michaelian, Kourken, and John Sutton. 2013. Distributed cognition and memory research: History and current directions. Review of Philosophy and Psychology 4: 1-24. https://doi.org/10.1007/s13164-013-0131-x.

Michel, Christoph, and Albert Newen. 2010. Self-deception as pseudo-rational regulation of belief. Consciousness and Cognition 19: 731-744. https://doi.org/10.1016/j.concog.2010.06.019.

Neisser, Ulric. 1988. Five kinds of self-knowledge. Philosophical Psychology 1: 35-59. https://doi.org/10. 1080/09515088808572924.

Nelson, Katherine. 1998. Language in cognitive development: The emergence of the mediated mind. $1 \mathrm{st}$ ed. Cambridge University Press. https://doi.org/10.1017/CBO9781139174619.

Nelson, Katherine, and Robyn Fivush. 2004. The emergence of autobiographical memory: A social cultural developmental theory. Psychological Review 111: 486-511. https://doi.org/10.1037/0033-295X.111.2. 486.

Newen, Albert. 2018. The embodied self, the pattern theory of self, and the predictive mind. Frontiers in Psychology 9: 2270. https://doi.org/10.3389/fpsyg.2018.02270.

Newen, Albert, and Petra Vetter. 2017. Why cognitive penetration of our perceptual experience is still the most plausible account. Consciousness and Cognition 47: 26-37. https://doi.org/10.1016/j.concog.2016. 09.005 .

Nigro, Georgia, and Ulric Neisser. 1983. Point of view in personal memories. Cognitive psychology 15.4: $467-482$.

Özbek, Müge, Annette Bohn, and Dorthe Berntsen. 2017. Imagining the personal past: Episodic counterfactuals compared to episodic memories and episodic future projections. Memory \& Cognition 45: 375-389. https://doi.org/10.3758/s13421-016-0671-2.

Pascuzzi, Debora, and Andrea Smorti. 2017. Emotion regulation, autobiographical memories and life narratives. New Ideas in Psychology 45: 28-37. 
Pasupathi, Monisha, Emma Mansour, and Jed R. Brubaker. 2007. Developing a life story: Constructing relations between self and experience in autobiographical narratives. Human development 50.2-3: 85110.

Pasupathi, Monisha. 2001. The social construction of the personal past and its implications for adult development. Psychological Bulletin 127: 651-672. https://doi.org/10.1037/0033-2909.127.5.651.

Prebble, Sally C., Donna Rose Addis, and Lynette J. Tippett. 2013. Autobiographical memory and sense of self. Psychological Bulletin 139: 815-840. https://oi.org/10.1037/a0030146.

Rathbone, Clare J., and Chris JA Moulin. 2017. Switch costs in the self-memory system. Quarterly Journal of Experimental Psychology 70.6: 1063-1073.

Rathbone, Clare J., Christopher J.A. Moulin, and Martin A. Conway. 2008. Self-centered memories: The reminiscence bump and the self. Memory \& Cognition 36: 1403-1414. https://doi.org/10.3758/MC.36.8. 1403.

Rau, Philipp. 2016. The author, not the tale: Memory, narrative, and the self. Sheffield: University of Sheffield.

Rubin, David C., Dorthe Berntsen, Samantha A. Deffler, and Kaitlyn Brodar. 2019. Self-narrative focus in autobiographical events: The effect of time, emotion, and individual differences. Memory \& Cognition 47: 63-75. https://doi.org/10.3758/s13421-018-0850-4.

Schacter, Daniel L., and Donna Rose Addis. 2007. The ghosts of past and future. Nature 445.7123: 27-27.

Schechtman, Marya. 2007. Stories, lives, and basic survival: A refinement and defense of the narrative view. Royal Institute of Philosophy Supplement 60: 155-178. https://doi.org/10.1017/S1358246107000082.

Sedikides, Constantine, and Jeffrey D. Green. 2009. Memory as a self-protective mechanism: Memorial selfprotection. Social and Personality Psychology Compass 3: 1055-1068. https://doi.org/10.1111/j.17519004.2009.00220.x.

Singer, Jefferson A., and Pavel Blagov. 2004. The integrative function of narrative processing: Autobiographical memory, self-defining memories, and the life story of identity. In the self and memory, 117-138. Studies in Self and Identity. New York: Psychology Press.

Singer, Jefferson A., Pavel Blagov, Meredith Berry, and Kathryn M. Oost. 2013. Self-defining memories, scripts, and the life story: Narrative identity in personality and psychotherapy. Journal of Personality 81 : 569-582. https://doi.org/10.1111/jopy.12005.

Singer, Jefferson A., and Susan Bluck. 2001. New perspectives on autobiographical memory: The integration of narrative processing and autobiographical reasoning. Review of General Psychology 5: 91-99. https:// doi.org/10.1037/1089-2680.5.2.91.

Strawson, Galen. 2004. Against Narrativity. Ratio 17: 428-452. https://doi.org/10.1111/j.1467-9329.2004. 00264.x.

Strawson, Galen. 2018. Things that bother me: Death, freedom, the self, etc. New York Review Books Classics. New York: New York Review Books.

Strawson, Galen. 2020. On the use of the notion of narrative in ethics and psychology. In the natural method: Essays on mind, ethics, and self in honor of Owen Flanagan, ed. Eddy Nahmias, Thomas W. Polger, and Wenqing Zhao. Cambridge: MIT press. https://doi.org/10.7551/mitpress/10567.003.0007.

Suddendorf, Thomas, and Michael C. Corballis. 2007. The evolution of foresight: What is mental time travel, and is it unique to humans? Behavioral and brain sciences 30. Cambridge University press: 299-313. Cambridge Core. https://doi.org/10.1017/S0140525X07001975.

Sui, Jie. 2016. Self-reference acts as a Golden thread in binding. Trends in Cognitive Sciences 20: 482-483. https://doi.org/10.1016/j.tics.2016.04.005.

Sui, Jie, and Glyn W. Humphreys. 2015. The integrative self: How self-reference integrates perception and memory. Trends in Cognitive Sciences 19: 719-728. https://doi.org/10.1016/j.tics.2015.08.015.

Sutin, Angelina R., and Richard W. Robins. 2007. Phenomenology of autobiographical memories: The memory experiences questionnaire. Memory 15.4: 390-411.

Symons, Cynthia S., and Blair T. Johnson. 1997. The self-reference effect in memory: A meta-analysis. Psychological Bulletin 121: 371-394. https://doi.org/10.1037/0033-2909.121.3.371.

Trope, Yaacov, and Nira Liberman. 2010. Construal-level theory of psychological distance. Psychological Review 117: 440-463. https://doi.org/10.1037/a0018963.

Uzer, Tugba, Peter J. Lee, and Norman R. Brown. 2012. On the prevalence of directly retrieved autobiographical memories. Journal of Experimental Psychology: Learning, Memory, and Cognition 38.5: 1296.

Valenti, Greta, Lisa K. Libby, and Richard P. Eibach. 2011. Looking back with regret: Visual perspective in memory images differentially affects regret for actions and inactions. Journal of Experimental Social Psychology 47: 730-737. https://doi.org/10.1016/j.jesp.2011.02.008.

Vallacher, Robin R., and Daniel M. Wegner. 1987. What do people think they're doing? Action identification and human behavior. Psychological Review 94: 3-15. https://doi.org/10.1037/0033-295X.94.1.3. 
Vallacher, Robin R., and Daniel M. Wegner. 1989. Levels of personal agency: Individual variation in action identification. Journal of Personality and Social Psychology 57: 660-671. https://doi.org/10.1037/00223514.57.4.660

Vallacher, Robin R., and Daniel M. Wegner. 2011. Action identification theory. In handbook of theories of social psychology, ed. Paul van Lange, Arie W. Kruglanski, and E. Troy Higgins, 1:327-348. London: SAGE publications ltd. https://doi.org/10.4135/9781446249215.n17.

Wang, Qi. 2008. Being American, being Asian: The bicultural self and autobiographical memory in Asian Americans. Cognition 107.2: 743-751.

Wang, Qi, Van-Kim Bui, and Qingfang Song. 2015. Narrative organisation at encoding facilitated children's long-term episodic memory. Memory 23.4: 602-611.

Wilson, Anne, and Michael Ross. 2003. The identity function of autobiographical memory: Time is on our side. Memory 11. Routledge: 137-149. https://doi.org/10.1080/741938210.

Wood, Wendy-Jo, and Michael Conway. 2006. Subjective impact, meaning making, and current and recalled emotions for self-defining memories. Journal of Personality 74: 811-845. https://doi.org/10.1111/j.14676494.2006.00393.x.

Publisher's Note Springer Nature remains neutral with regard to jurisdictional claims in published maps and institutional affiliations. 